\title{
PRODUÇÃO CIENTÍFICA SOBRE ANÁLISE DO DISCURSO NA ENFERMAGEM E REFERENCIAIS TEÓRICOS UTILIZADOS
}

\author{
I. C. A. SCHIAVON*, E. C. OLIVEIRA*, S. C. ANDRADE* e J. C. GONÇALVES** \\ *Instituto Federal de Educação, Ciência e Tecnologia do Sudeste de Minas Gerais \\ ** Universidade Federal Fluminense \\ Isabel.schiavon@ifsudestemg.edu.br
}

Submetido 01/04/2016 - Aceito 01/09/2017

DOI: $10.15628 /$ holos.2017.3940

\section{RESUMO}

A Análise do Discurso se destaca como uma ferramenta relevante para o campo da saúde, pois permite um entendimento mais claro do processo saúde-doença ao buscar uma aproximação do profissional com uma interpretação da linguagem do usuário. Neste contexto, essa pesquisa buscou identificar e analisar, por meio da literatura científica nacional e internacional, as contribuições das teorias da Análise do Discurso para a Enfermagem e os referenciais teóricos mais utilizados. $O$ estudo revelou que a Análise de Discurso de vertente Francesa foi a mais prevalente, Michel Foucault o autor mais citado e apontou ainda a escassez de estudos sobre essa temática no âmbito nacional.

PALAVRAS-CHAVE: Enfermagem, Análise do Discurso, Pesquisa em Enfermagem.

\section{SCIENTIFIC LITERATURE ON DISCOURSE ANALYSIS IN NURSING AND THEORETICAL FRAMEWORKS USED}

\begin{abstract}
Discourse Analysis stands out as a relevant tool in the field of health, since it allows a clearer understanding of the health-disease process by seeking an approach of the professional with the interpretation of the user's language. In this context, this research sought to identify and analyze, through the national and international scientific literature, the contributions of Discourse
\end{abstract}

Analysis theories for Nursing and the most used theoretical references. The study revealed that the French Discourse Analysis was the most prevalent, Michel Foucault the most cited author and also pointed to the scarcity of studies on this subject at the national level.

KEYWORDS: Nursing, Discourse Analysis, Nursing Research. 


\section{INTRODUÇÃO}

As teorias da Análise do Discurso (AD) englobam uma ampla variedade de correntes de pensamentos com métodos, técnicas de tratamento e análise por meio de abordagens interdisciplinares e multidisciplinares, tendo em comum o interesse na investigação da linguagem em uso. Baseiam-se na concepção da linguagem como uma ferramenta para dizer, fazer e ser e não simplesmente uma ferramenta passiva para a representação da realidade (Beedholm, Lomborg, \& Frederiksen, 2013).

No entendimento de Paulon, Nascimento e Laruccia (2014), a obra Discourse Analysis (1952) pode ser considerada o marco inicial das teorias da $A D$, uma vez que nela há a proposta do autor para se expandir o método de análise para além de uma frase. Contudo, há controvérsias a respeito das suas origens epistêmicas, já que autores como Eisenhart e Johnstone (2013) apontam a Filogenia do século XIX como as suas raízes históricas.

Os anos 60 foram significativos para o desenvolvimento da $A D$, pois a partir desse ponto se vivenciou uma importante ruptura que afetou o contexto intelectual da época: por um lado, a linguagem passa a ser vista como um ramo muito complexo e, portanto, não mais cabendo dentro dos limites saussurianos. Rompe-se nesse ponto com a ideia de que o sentido é dado apenas pelo conteúdo, redirecionando-se a análise para o entendimento do funcionamento de um texto. Por outro lado, a forma como a leitura é entendida pelos intelectuais também muda. A partir de então, esta passa a não ser mais concebida como uma ferramenta de decodificação, mas como a construção de um dispositivo teórico.

Nesse contexto, surge a $A D$ de vertente francesa trazendo para a discussão linguística tópicos importantes como a fala, o sujeito, a ideologia, o social, a história e a semântica. Conforme nos relata Orlandi (2007): "procura-se compreender a língua não só como uma estrutura, mas, sobretudo como acontecimento" (p.19).

A AD começa a se ocupar de questões relevantes como a interpretação e a inclusão da memória com seu estatuto político e social. Passa-se a buscar o entendimento do fenômeno da linguagem não mais centrado na própria língua, mas em um outro nível, o discurso. Importante também se ressaltar que a $A D$ nasce da interdisciplinaridade entre a relação das disciplinas de Linguística, Marxismo e Psicanálise. Dessa forma, o discurso é entendido como tridimensional, uma vez que seu surgimento se dá pela intersecção do linguístico com o histórico e o ideológico.

Assim, para se definir o sujeito é importante que se conheça sua posição ideológica, 
marcada pelo seu espaço social, papel desempenhado e lugar que ocupa nesse contexto. Isto é, ao se analisar um discurso, considera-se o homem inserido em uma história e a linguagem é uma produção gerada a partir da relação entre a língua com os sujeitos e também do contexto em que a mesma é produzida e falada.

O objetivo da $A D$ é verificar em que condições se deu o aparecimento de um discurso específico, analisando o porquê determinado sentido foi tomado em detrimento de outro. Em suma, buscar a compreensão dos processos em que o sentido é produzido e a constituição dos sujeitos em suas posições (Gondim \& Fischer, 2009).

Suas contribuições para o campo da saúde são diversas e autores como Macedo, Larocca, Chaves e Mazza (2008) a destacam como importante ferramenta para entendimento do processo saúde-doença na medida em que busca uma aproximação do mesmo com a interpretação da linguagem. Segundo os autores, a forma como as palavras são estruturadas podem definir os discursos e, por conseguinte, possibilitar o entendimento tanto dos fenômenos quanto dos conceitos implicados para a compreensão dos processos de subjetivações dos sujeitos em seu itinerário com a doença ou busca por saúde.

Minayo (2004) amplia o escopo de significação da análise no campo da saúde quando esclarece que pela palavra há a exposição das contradições e conflitos presentes em determinada realidade, uma vez que a palavra é construída em meio à ideologia e grupo social em dada época, assim, compreender o discurso, exige que se compreenda as relações sociais expressas por ele.

A saúde e a doença são condições também produzidas na estrutura social, fazendo parte de uma realidade complexa, a qual trabalha simultaneamente com problemas e intervenções, requerendo múltiplos conhecimentos específicos, mas ao mesmo tempo, integrados. Essa realidade em saúde faz com que a pesquisa qualitativa seja muito relevante nessa área. Dentre as variadas possibilidades interpretativas na pesquisa qualitativa, Minayo (2004) aponta a AD como o método mais adequado para a compreensão dos fenômenos, colaborando na reflexão acerca das condições de produção e apreensão dos significados de textos produzidos em variados campos, inclusive no campo da saúde.

A AD permite uma compreensão profunda do texto ao considerar a realidade social e histórica de sua produção. Segundo Fiorin (2005): "é o discurso que vai revelar quem é o sujeito, qual é a sua visão de mundo" (p.49). Sua utilização pela área da saúde "permite uma compreensão mais dinâmica do texto, reconhecendo e interpretando as concepções sobre um 
determinado objeto de acordo com o contexto onde foi produzido" (Vianna \& Barros, 2003, p. 59).

A área de Enfermagem tem como compromisso produzir cuidados integrais de saúde voltados ao atendimento das necessidades de saúde do paciente/cliente/comunidade nas diferentes fases do ciclo vital, tanto no âmbito dos serviços públicos de saúde, quanto nos serviços privados. Acresce-se a isso, o compromisso com a integração com outros setores econômicos e sociais, relevantes para as condições de saúde, individual e coletivas, e que irão interferir no nível da saúde da comunidade e na organização dos serviços. O desenvolvimento de um cuidado humanizado passa pela necessidade da ampliação do cuidado para além do corpo biológico, de acordo com Duarte, Dittz, Silva e Rocha (2013). Enfatizam ainda, a necessidade de que o profissional de enfermagem tenha uma gama de conhecimentos, fundamentados no saber, ser, sentir e fazer, que lhe permita prestar cuidados efetivos ao cliente, além de interagir com demais profissionais da saúde, na busca de um atendimento integral.

A concretização desse perfil dar-se-á através de uma formação que proporcione aos futuros profissionais a capacidade de se verem e se conhecerem, ou seja, uma nova postura baseada na consciência crítica e na capacidade de encontrar e associar informações, de trabalhar em grupo, de se comunicar com desenvoltura, saber lidar com imprevistos e se adaptar rapidamente às mudanças (Adão, Coimbra - Oliveira, Pederiva \& Camargos, 2016).

Frente à complexidade das políticas de saúde brasileiras, ao modelo assistencial proposto pelo Sistema Único de Saúde (SUS) e aos avanços científicos e tecnológicos, a Enfermagem vive um momento em que se propõem mudanças, centrando as ações num modelo planejado a partir das necessidades de saúde da população, garantindo e viabilizando o direito de todos a um serviço capaz de suprir suas necessidades de forma integral (Schiavon, 2012). A inter, a multi e a transdisciplinaridade; enfatizam o pensamento sistêmico, concebem informação como matériaprima que o conhecimento deve dominar e entendem que o conhecimento deve ser permanentemente revisitado e revisado pelo pensamento, e que o pensamento é, mais que nunca, o capital mais precioso para o indivíduo e a sociedade (Morin, 2001). A partir daí, será possível atuar na formação de sujeitos ativos, críticos, reflexivos, conscientes acerca de seu papel enquanto agentes transformadores da sociedade (Freire, 2004).

Assim, o objeto deste estudo se constituiu nas evidências científicas sobre a produção científica nacional e internacional da Enfermagem sobre a análise do discurso e os referenciais teóricos mais utilizados. Considerando a natureza do objeto e a problemática apresentada, teve- 
se como questão norteadora desta pesquisa: Quais as contribuiç̧̃̃es da análise do discurso para a Enfermagem e quais os referenciais teóricos mais utilizados? Ante o exposto, nosso objetivo foi identificar e analisar por meio da literatura científica nacional e internacional, as contribuições científicas da análise do discurso para a Enfermagem com ênfase nos referenciais teóricos mais utilizados para essa finalidade.

\section{METODOLOGIA}

Trata-se de uma revisão integrativa de literatura, cuja trajetória metodológica seguiu as seis etapas pertinentes a esse método, sendo elas: a escolha da temática e delimitação da questão norteadora; definição dos critérios de inclusão e exclusão dos estudos e a busca; categorização dos estudos; avaliação dos estudos incluídos na revisão; interpretação dos resultados; síntese do conhecimento (Mendes, Silveira \& Galvão, 2008).

Segundo Souza, Silva e Carvalho (2010), a revisão integrativa é "um método que proporciona a síntese de conhecimento e a incorporação da aplicabilidade de resultados de estudos significativos na prática" (p.102). A sua realização consiste na possibilidade de desenvolvimento de modelos de pesquisa que possam fornecer subsídios para a geração de mudanças que se revertam em melhoria na qualidade das práticas assistenciais e de formação em Enfermagem. A pergunta norteadora da presente revisão integrativa consistiu em: Qual a contribuição da análise do discurso para a área de Enfermagem e quais os referenciais teóricos mais utilizados?

Tomou-se como recorte temporal os últimos dez anos, ou seja, aqueles que foram publicados entre 2005 e 2015. Os critérios de inclusão dos estudos pesquisados foram: estudos indexados nas bases de dados: Literatura Latino-Americana em Ciências da Saúde (LILACS), Scientific Electronic Library Online (SciELO), Instituto Brasileiro de Informação em Ciência e Tecnologia (IBICT); estudos publicados nos últimos dez anos; estudos que possuíam textos completos disponíveis e artigos nos idiomas português e inglês.

Após seleção dos descritores pesquisados nos Descritores em Ciência da Saúde (DeCS) da Biblioteca Virtual em Saúde (BVS): Enfermagem e análise do discurso em português e discourse analysis and Nursing em inglês, foi feito o cruzamento dos mesmos e obtida uma amostragem que permitiu inicialmente a leitura do título e dos resumos disponíveis. 
$\mathrm{Na}$ base de dados LILACS encontramos cinco artigos, no IBICT encontramos seis estudos entre tese e dissertações. Na base de dados SciELO encontramos dois artigos que já haviam sido encontrados pelo LILACS, sendo assim excluídos.

Para cada documento da amostra do estudo foi preenchido um formulário de coleta de dados. Este formulário permitiu informações concisas sobre o documento e seus autores; fonte de localização; objetivos e delineamento do estudo.

A amostra final ficou constituída por 11 documentos sobre AD na Enfermagem. Embora a base de dados SciELO tenha apresentado alguns artigos na primeira busca, ao se submeter a população identificada aos critérios de exclusão, não houve seleção de artigo para composição da amostra.

A base de dados LILACS forneceu o maior número de estudos para a composição da amostra, seis. Acreditamos que o fato de ser uma base de dados internacional e englobar inúmeros países americanos e europeus, aliados ao idioma selecionado, inglês, tenha favorecido nessa seleção.

O IBICT forneceu cinco estudos para composição da amostra. Consideramos que por ser a maior base de dados brasileira, reunindo a grande parte das universidades nacionais e o fato de que o idioma selecionado nesse momento da busca tenha sido o português, essa base dados mesmo fornecendo uma população ligeiramente menor, tenha contribuído de forma relevante para compor a amostra.

A seleção dos resumos levou em consideração a análise daqueles que possuíam título e assunto relacionados com o estudo em questão. A apresentação dos resultados e a discussão dos dados obtidos foram feitas de forma descritiva e foram construídas categorias de análise temáticas e categorias relacionadas aos referenciais teóricos mais utilizados.

\section{RESULTADOS E DISCUSSÃO}

A busca realizada em base de dados para a composição da amostra deste estudo conseguiu elencar 13 estudos. Durante a etapa de tratamento e classificação dos estudos, dois foram descartados devido à inconsistência de informações sobre a concreta utilização das teorias da $A D$ assim como dos seus métodos e instrumentos. 
No Quadro 1 são apresentadas algumas características relacionadas à amostra selecionada.

Quadro 1 - Características relacionadas às publicações, São João del-Rei, 2015.

\begin{tabular}{|c|c|c|c|c|}
\hline Literatura & Periódico & $\begin{array}{c}\text { Fonte ou Base de } \\
\text { Dados }\end{array}$ & $\begin{array}{c}\text { Ano de } \\
\text { publicação }\end{array}$ & Tipo de publicação \\
\hline $\begin{array}{l}\text { Contradictory discourses of } \\
\text { health promotion and disease } \\
\text { prevention in the educational } \\
\text { curriculum of Norwegian public } \\
\text { health nursing: A critical } \\
\text { discourde analysis }\end{array}$ & $\begin{array}{c}\text { Scandinavian } \\
\text { Journal of Public } \\
\text { Health } \\
\text { País: } \\
\text { Escandinávia }\end{array}$ & LILACS & 2014 & Artigo \\
\hline $\begin{array}{l}\text { Discourse analysis and the } \\
335 \text { ontext335f the philosophy } \\
\text { of Enlighttenment in nursing } \\
\text { research }\end{array}$ & $\begin{array}{l}\text { Nursing Inquiry } \\
\text { País: Inglaterra }\end{array}$ & LILACS & 2014 & Artigo \\
\hline $\begin{array}{l}\text { Doing Foucault: inquiring into } \\
\text { nursing knowledge with } \\
\text { Foucauldian discourse analysis }\end{array}$ & $\begin{array}{c}\text { Nursing } \\
\text { Philosophy } \\
\text { País: Inglaterra }\end{array}$ & LILACS & 2015 & Artigo \\
\hline $\begin{array}{l}\text { Governing nursing through } \\
\text { reflection: A discourse analysis } \\
\text { of reflective practices }\end{array}$ & $\begin{array}{l}\text { Journal of } \\
\text { Advanced } \\
\text { Nursing } \\
\text { País: Inglaterra }\end{array}$ & LILACS & 2008 & Artigo \\
\hline $\begin{array}{l}\text { Healh promotion in nursing: a } \\
\text { derridean discourse analysis }\end{array}$ & $\begin{array}{c}\text { Health } \\
\text { Promotion } \\
\text { International } \\
\text { País: Inglaterra }\end{array}$ & LILACS & 2011 & Artigo \\
\hline $\begin{array}{l}\text { The influence of protection, } \\
\text { palliation and costs on mobility } \\
\text { optimization of residentes in } \\
\text { nursing homes: a thematic } \\
\text { analysis of discourse. }\end{array}$ & $\begin{array}{l}\text { International } \\
\text { Journal of } \\
\text { Nursing Studies } \\
\text { País: Inglaterra }\end{array}$ & LILACS & 2012 & Artigo \\
\hline $\begin{array}{l}\text { A Questão Ético-Moral na } \\
\text { Formação dos Enfermeiros e } \\
\text { Médicos: efeitos de sentidos } \\
\text { nos discursos docentes }\end{array}$ & Não se aplica & $\begin{array}{l}\text { Biblioteca da } \\
\text { Universidade } \\
\text { Federal do Rio } \\
\text { Grande do Sul }\end{array}$ & 2008 & Tese \\
\hline $\begin{array}{l}\text { O exercício da atividade da } \\
\text { enfermeira obstétrica: análise } \\
\text { do discurso médico no Rio } \\
\text { Grande do Sul no ano de } 2005\end{array}$ & Não se aplica & $\begin{array}{l}\text { Biblioteca da } \\
\text { Universidade } \\
\text { Federal do Rio } \\
\text { Grande do Sul }\end{array}$ & 2008 & Dissertação \\
\hline $\begin{array}{l}\text { Princípio da integralidade no } \\
\text { processo de formação do } \\
\text { técnico de enfermagem das } \\
\text { Escolas das REDE SUS }\end{array}$ & Não se aplica & $\begin{array}{c}\text { Biblioteca da } \\
\text { Universidade } \\
\text { Federal de Santa } \\
\text { Catarina } \\
\end{array}$ & 2013 & Dissertação \\
\hline $\begin{array}{l}\text { Representações sociais de } \\
\text { idosos sobre o ato de ser } \\
\text { cuidado em instituição asilar. }\end{array}$ & Não se aplica & $\begin{array}{c}\text { Biblioteca da } \\
\text { Universidade } \\
\text { Federal da Bahia }\end{array}$ & 2009 & Dissertação \\
\hline $\begin{array}{l}\text { Trabalho e subjetividade no } \\
\text { contexto hospitalar: Análise } \\
\text { institucional do discurso } \\
\text { produzido em grupo com } \\
\text { profissionais de enfermagem da } \\
\text { pediatria }\end{array}$ & Não se aplica & $\begin{array}{l}\text { Biblioteca da } \\
\text { Universidade de } \\
\text { São Paulo }\end{array}$ & 2013 & Dissertação \\
\hline
\end{tabular}

Fonte: Elaboração própria, 2015. 
Conforme podemos constatar, as publicações foram extraídas de diversos periódicos, no entanto, a maioria deles são ingleses (4), apenas um periódico é da Escandinávia. Considerando ser a Inglaterra o berço da Enfermagem Moderna e possuir larga tradição no ensino e estudos acerca de temas da Enfermagem, explica-se esse achado na pesquisa em questão. Das bibliotecas pesquisadas, observou-se que o maior número de estudos (2) foi proveniente da Biblioteca da Universidade Federal do Rio Grande do Sul (UFRGS). A área de Enfermagem da UFRGS possui sólida tradição na produção científica. Segundo dados do Programa de Pós-graduação em Enfermagem da UFRGS, em 2014 foram 37 estudos defendidos nessa universidade entre teses e dissertações (UFRGS, 2015), evidenciando a notável produção científica oriunda dessa universidade. A Escola de Enfermagem do Rio Grande do Sul iniciou suas atividades em 1950 e é a mais antiga Escola de Enfermagem da região sul. Possui três cursos de graduação, dois de pósgraduação strictu sensu (Mestrado e Doutorado) e publica a Revista Gaúcha de Enfermagem, considerada uma das mais influentes na Enfermagem brasileira.

O período das publicações foi de 2008 a 2015 com predominância do ano de 2008 (3).

No Quadro 2, analisamos as contribuições dos estudos à área da Enfermagem e o referencial teórico mais utilizado.

Quadro 2 - Contribuições da análise do discurso à Enfermagem apontadas pelos estudos e referenciais teóricos utilizados, São João del-Rei, 2015.

\begin{tabular}{|c|c|}
\hline Literatura & $\begin{array}{l}\text { Contribuições apontadas pelos estudos e referencial teórico } \\
\text { utilizado }\end{array}$ \\
\hline $\begin{array}{l}\text { Contradictory discourses of health } \\
\text { promotion and disease prevention in the } \\
\text { educational curriculum of Norwegian } \\
\text { public health nursing: A critical discourse } \\
\text { analysis }\end{array}$ & $\begin{array}{l}\text { Analisar a formação do enfermeiro (Categoria: Formação em } \\
\text { Enfermagem) } \\
\text { Referencial Teórico: Norman Fairclough (Análise Crítica do Discurso) }\end{array}$ \\
\hline $\begin{array}{l}\text { Discourse analysis and the impact of the } \\
\text { philosophy of Enlightenment in nursing } \\
\text { research }\end{array}$ & $\begin{array}{l}\text { Discutir a aplicação da análise do discurso na pesquisa em Enfermagem } \\
\text { (Categoria: Pesquisa em Enfermagem) } \\
\text { Referencial Teórico: Michel Foucault (Análise do Discurso Francesa) }\end{array}$ \\
\hline $\begin{array}{l}\text { Doing Foucault: inquiring into nursing } \\
\text { knowledge with Foucauldian discourse } \\
\text { analysis }\end{array}$ & $\begin{array}{l}\text { Analisar a construção do conhecimento na Enfermagem (Categoria: } \\
\text { Construção do Conhecimento) } \\
\text { Referencial Teórico: Michel Foucault (Análise do Discurso Francesa) }\end{array}$ \\
\hline $\begin{array}{l}\text { Governing nursing through reflection: } A \\
\text { discourse analysis of reflective practices }\end{array}$ & $\begin{array}{l}\text { Permitir a prática reflexiva na Enfermagem (Categoria: Prática Reflexiva) } \\
\text { Referencial Teórico: Michel Foucault ( Análise do Discurso Francesa) }\end{array}$ \\
\hline $\begin{array}{l}\text { Healh promotion in nursing: a Derridean } \\
\text { discourse analysis }\end{array}$ & $\begin{array}{l}\text { Analisar o verdadeiro papel do enfermeiro na promoção à saúde } \\
\text { (Categoria: Atuação Profissional) } \\
\text { Referencial Teórico: Jacques Derrida (Desconstrução) }\end{array}$ \\
\hline $\begin{array}{l}\text { The influence of protection, palliation and } \\
\text { costs on mobility optimization of }\end{array}$ & $\begin{array}{l}\text { Analisar o conhecimento dos enfermeiros sobre a segurança do } \\
\text { paciente (Categoria: Construção do Conhecimento) }\end{array}$ \\
\hline
\end{tabular}




\begin{tabular}{|c|c|}
\hline $\begin{array}{l}\text { in nursing ho } \\
\text { of discourse. }\end{array}$ & ) \\
\hline $\begin{array}{l}\text { A Questão Ético-Moral na Formação dos } \\
\text { Enfermeiros e Médicos: efeitos de } \\
\text { sentidos nos discursos docentes }\end{array}$ & $\begin{array}{l}\text { Refletir sobre a formação dos profissionais de Enfermagem (Categori } \\
\text { Formação em Enfermagem) } \\
\text { Referencial Teórico: Michel Pêcheux (Análise do Discurso Francesa) }\end{array}$ \\
\hline $\begin{array}{l}\text { O exercício da atividade da enfermeira } \\
\text { obstétrica: análise do discurso médico no } \\
\text { Rio Grande do Sul no ano de } 2005\end{array}$ & $\begin{array}{l}\text { Evidenciar a legalidade na atuação da enfermeira obstétrica no parto, } \\
\text { mas não a legitimidade social e profissional Categoria: Atuação } \\
\text { Profissional) } \\
\text { Referencial Teórico: Michel Pêcheux (Análise do Discurso Francesa) }\end{array}$ \\
\hline $\begin{array}{l}\text { Princípio da integralidade no processo de } \\
\text { formação do técnico de enfermagem das } \\
\text { Escolas das REDE SUS }\end{array}$ & $\begin{array}{l}\text { Discutir a integralidade na formação do Técnico em Enfermagem ( } \\
\text { Categoria: Formação em Enfermagem) } \\
\text { Referencial Teórico: Fernando Lefévre e Ana Maria Levéfre (Discurso do } \\
\text { Sujeito Coletivo) }\end{array}$ \\
\hline $\begin{array}{l}\text { entações sociais d } \\
\text { ser cuidado em ins }\end{array}$ & $\begin{array}{l}\text { Refletir sobre o cuidado prestado ao idoso em instituições de longa } \\
\text { permanência (Categoria: Prática Reflexiva) } \\
\text { Referencial Teórico: Fernando Lefévre (Discurso do Sujeito Coletivo) }\end{array}$ \\
\hline $\begin{array}{l}\text { Trabalho e subjetividade no contexto } \\
\text { hospitalar: Análise institucional do } \\
\text { discurso produzido em grupo com } \\
\text { profissionais de enfermagem da pediatria }\end{array}$ & $\begin{array}{l}\text { Permite a investigação sobre o trabalho dos profissionais de saúde e } \\
\text { enfermagem, além de suas relações com o setor e instituição em que } \\
\text { trabalham e sua clientela (Categoria: Trabalho em Enfermagem) } \\
\text { Referencial Teórico: Marlene Guirado (Análise Institucional do Discurso) }\end{array}$ \\
\hline
\end{tabular}

Fonte: Elaboração própria, 2015.

Com base nas informações sintetizadas no Quadro 2, observamos que o referencial teórico mais utilizado foi a Análise do Discurso Francesa, sendo Michel Foucault o autor mais citado.

Estudo desenvolvido por Costa, Ramos e Padilha (2008) no Banco de Teses e Dissertações da Universidade Federal de Santa Catarina no período de 1978 a 2006, apontou a presença de 13 estudos que utilizaram Foucault como referencial teórico/metodológico. Segundo as autoras, Foucault aborda temas que são relevantes para a Enfermagem como as questões de poder, os saberes, lutas e estratégias, os quais permitem um novo olhar sobre os diversos campos de atuação na área. Abrem uma perspectiva de análise das práticas assistenciais ao buscar o entendimento sobre como as verdades são instituídas e como as relações de poder operam no interior dos serviços de saúde e nas ações institucionalizadas. Ao propor uma análise crítica da realidade, Foucault nos incita à percepção dos problemas específicos que vem se constituindo e sustentando nossa realidade profissional (Costa, Ramos \& Padilha, 2008).

Sobre os temas mais recorrentes nos estudos enfocados, notou-se a preocupação dos autores em discutir a formação em Enfermagem (3) e a construção do conhecimento (2). Cabe um ressalte nessa observação, embora tratem de duas categorias temáticas distintas, ambas 
discutem como se dá a apropriação do conhecimento em Enfermagem pelo profissional durante sua formação. Supomos ser essa uma preocupação justificada na medida em que orienta para um perfil profissional que atenda aos pressupostos da profissão que se alinha com o recomendado por organismos internacionais da área da Enfermagem e pelo próprio Ministério da Educação, o qual preconiza:

Enfermeiro, com formação generalista, humanista, crítica e reflexiva. Profissional qualificado para o exercício de Enfermagem, com base no rigor científico e intelectua I e pautado em princípios éticos. Capaz de conhecer e intervir sobre os problemas/situações de saúde-doença mais prevalentes no perfil epidemiológico nacional, com ênfase na sua região de atuação, identificando as dimensões bio-psico- sociais dos seus determinantes. Capacitado a atuar, com senso de responsabilidade social e compromisso com a cidadania, como promotor da saúde integral do ser humano (Ministério da Educação, 2001, p. 1)

Assim, o modelo biomédico, mecanicista e hegemônico já não atende mais às necessidades de formação do profissional de Enfermagem, uma vez que o novo modelo, holístico, deslocou o cuidado, antes centrado nos procedimentos de cura e desenvolvido em ambiente hospitalar para o modelo centrado no usuário e desenvolvido na comunidade. Com isso, o cuidar adquiriu uma nova dimensão e o seu objeto de trabalho transcendeu às práticas assistencialistas. Cuidar nesse novo contexto requer novas competências, habilidades e atitudes, em um processo contínuo de diálogo entre a educação e a saúde, embasados em uma filosofia que dê suporte para o pleno exercício dessa nova prática.

\section{Categorias relacionadas aos referenciais teóricos utilizados nos estudos}

\section{Análise do Discurso Francesa}

Busca analisar construções ideológicas de um texto. A análise do discurso (AD) afirma que o discurso não é uma construção individual, mas social e que deve ser considerado em meio a um contexto histórico-social e suas condições de produção, ou seja, o discurso reflete uma visão de mundo determinada, e que se encontra interligada aos seus autores e ao meio social do qual fazem parte. Surgiu na França em 1969, com o livro de Michel Pêcheaux, Analyse Automatique du Discours. Pêcheaux criou um espaço de discussão chamado de entremeio em que buscava o confronto entre as Ciências Humanas, particularmente a História, a Linguística e a Psicanálise, 
pois julgava que as mesmas eram elitizadas e isoladas. Contemporâneo a Pêcheaux, está Michel Foucault, que em seu livro "Arqueologia do Saber" (1969), propõe uma outra via de compreensão, discutindo os jogos de poder na evolução do discurso da sociedade, criando dentro da AD, um outro caminho teórico (Azevedo, 2013).

\section{Análise Crítica do Discurso}

A partir do livro "Language and Control" de Fowler e Kress (1979), surge uma vertente preocupada com o trabalho do discurso como prática social, mas com bases e conceitos extremamente diferenciados dos desenvolvidos pela AD (Melo, 2009). A produção teórica da Análise Crítica do Discurso (ACD) surge a partir dos diálogos entre a Linguística e a Ciência Social Crítica, colocando o diálogo em posição central, dando ao mesmo o reconhecimento como uma prática social. Santos, Bispo e Dourado (2015) classificam a ACD como “(...) uma abordagem teórico-metodológica que vê o discurso como uma prática social, através da qual as pessoas podem agir sobre o mundo e sobre os outros" (p.56).

A Análise Crítica do Discurso caracteriza-se como um campo de estudo em oposição tanto das estruturas quanto às estratégias do discurso das elites. Seu princípio norteador baseia-se na afirmativa de que o discurso é constituído e se constitui nas práticas sociais, revelando os processos de manutenção e abuso de poder, ou ainda, segundo Kress (1990, p. 85 citado por Melo, 2009, p. 9): “os analistas críticos do discurso pretendem mostrar o modo como as práticas linguístico-discursivas estão imbricadas com as estruturas sociopolíticas mais abrangentes de poder e dominação".

Suas bases epistemológicas são: os estudos anglo-saxãos da década de 70; as teorias neomarxistas, principalmente as de Gramsci e os estudos da Escola de Frankfurt.

Seus principais expoentes: Teun Van Dijk, Guinter Kress e Norman Fairclough.

\section{Desconstrução}

Trata-se de um trabalho de investigação que coloca sob suspeita os vários discursos ao questionar o conceito clássico de ciência. Seu início se dá em 1962 na introdução da tradução do livro "Origem da Geometria" de Edmund Husserl. Mas, segundo Haddock-Lobo (2014):

O ano de 1967 pode ser considerado como a grande estreia do pensamento de Derrida, com a publicação consecutiva de três livros que 
terão um grande impacto no panorama filosófico da época: A voz e o fenômeno, Gramatologia e A escritura e a diferença (os três disponíveis em língua portuguesa) (para. 3).

Busca minar as correntes hierárquicas do pensamento ocidental, causando nestas um forte impacto, uma vez que proporcionou questionamentos, deslocamentos, realocações de conceitos absolutos da época. Houve, a partir dessa teoria, uma abalo na hegemonia dos discursos ( Pedroso Júnior, 2010).

A Desconstrução é considerada como uma estratégia e não um método e sua natureza é lógica e não histórica ((Meneses, 2013).

Bases Epistemológicas: estudos fenomenológicos de Edmund Husserl, sobretudo aqueles que tratam do tema da intersubjetividade e obras de Heidegger.

Seu principal expoente: Jacques Derrida.

\section{Discurso do Sujeito Coletivo}

O Discurso do Sujeito Coletivo (DSC) foi desenvolvido por Lefévre e Lefévre no final da década de 90, tendo como fundamento a Teoria das Representações Sociais e consiste em uma técnica de tabulação e organização de dados qualitativos. Segundo Figueiredo, Chiari e Goulart (2013), o DSC "permite que se conheça os pensamentos, representações, crenças e valores de uma coletividade sobre determinado tema utilizando-se de métodos científicos" (p.130). Largamente utilizada nas pesquisas no campo da saúde, essa técnica mostra-se altamente eficaz no processamento e expressão das opiniões coletivas.

Sua base epistemológica: Teoria das Representações Sociais.

Seus expoentes: Fernando Levéfre e Ana Maria Lefévre.

\section{Análise Institucional do Discurso}

Em 2009, em sua tese de Livre-docência, Marlene Guirado, propõe a Análise Institucional do Discurso. Fazendo interface com o trabalho de Foucault, Guirado, por meio da AD, busca a "explicitação do modo como se dá o jogo de distribuição de lugares nas relações institucionais e dos sujeitos que aí se reconhecem" (Valore, 2005, p. 118). Procura identificar a relação dos sujeitos para com a instituição, definindo seu papel na estrutura de poder simbólico institucional. 
Suas bases epistemológicas: estudos de Michel Foucault, sobretudo aqueles que discutem as relações poder-saber, a constituição do sujeito moral e a singularidade possível na contemporaneidade.

Seu principal expoente: Marlene Ghirado.

\section{CONSIDERAÇÕES FINAIS}

Nesse estudo, os autores procuraram evidenciar a produção científica da Enfermagem sobre a $A D$ que se mostrou ainda incipiente, pois apenas 11 estudos trouxeram elementos que testificam essa afirmação. Observou-se que a $A D$ de vertente francesa foi a perspectiva teórica mais utilizada pelos pesquisadores nos estudos em questão, sendo Michel Foucault, o autor mais citado.

É digno de nota que alguns pesquisadores ainda consideram ser apenas da competência do linguista o trabalho com a teoria em pesquisas. Talvez esse fato seja intimista e esclareça o tímido resultado que se obteve neste estudo.

Acreditamos que a incorporação das ideias centrais da $A D$ poderiam contribuir na Enfermagem, não só no ensino, mas também nas pesquisas na área, trazendo à tona discussões e problemas muitas vezes negligenciados na formação do enfermeiro. A Enfermagem se constitui como campo de saber que apresenta uma vasta diversidade na sua organização e construção de seus instrumentais teóricos e técnicos. Repensar essa estrutura com vistas a ser capaz de emitir discursos coerentes sobre sua posição social, sua inserção científica e sobre si própria, são alguns dos grandes desafios da Enfermagem que a AD poderia contribuir em sua transposição.

Por fim, mostrou-se evidente a escassez de estudos sobre a temática abordada, sobretudo no âmbito nacional, em que excetuando-se os estudos de pós-graduação, não foram encontrados artigos para composição da amostra.

\section{REFERÊNCIAS}

Adão, I. C., Coimbra-Oliveira, E., Pederiva, A.C., \& Camargos, A. T. (2016). O desafio do ensino por competências na educação profissional em Enfermagem. Revista Eletrônica Debates em Educação Científica e Tecnológica. 6(3), 92-118.

Azevedo, S. D. R. (2013). Formação discursiva e discurso em Michel Foucault. Revista Eletrônica de Pesquisa na Graduação em Filosofia da UNESP - FILOGÊNESE, 6(2), 148-162. 
Beedholm, K., Frederiksen, K. (2014). Discourse analysis and the impact of the philosophy of Enlightnment in nursing research. Nursing Inquiry, 21 (2), 112-120.

Caregnato, R. C. A. (2008). A Questão Ético-Moral na Formação dos Enfermeiros e Médicos: efeitos de sentidos nos discursos docentes. Tese de Doutorado, Faculdade de Educação, Universidade Federal do Rio Grande do Sul, Porto Alegre.

Coelho, R. L. (2013). Trabalho e subjetividade no contexto hospitalar: Análise institucional do discurso produzido em grupo com profissionais de enfermagem da pediatria. Dissertação de Mestrado, Instituto de Psicologia, Universidade de São Paulo, São Paulo.

Costa, R., Souza, S. S., Ramos, F. R. S, \& Padilha, M. I. (2008). Foucault e sua utilização como referencial na produção científica em Enfermagem. Texto Contexto Enferm, 17 (4), 629 637.

Crowe, M. (2005). Discourse analysis: towards an understanding of its place in nursing. Journal of Advanced Nursing, 51(1), 55-63.

Dahl, B. M., Clancy, A. (2014). Contradictory discourses of health promotion and disease prevention in the educational curriculum of Norwegian public health nursing: A critical discourse analysis. Scandinavian Journal of Public Health, 42(1), 32-37.

Dal Molin, R. S. (2008). O exercício da atividade da enfermeira obstétrica: análise do discurso médico no Rio Grande do Sul no ano de 2005. Dissertação de Mestrado, Escola de Enfermagem, Universidade Federal do Rio Grande do Sul, Porto Alegre.

Duarte, E. D., Dittz, E. S., Silva, B. C. N., \& Rocha, L. L. B. (2013). Grupos de apoio às mães de recém-nascidos internados em unidade neonatal. Rev Rene, 4(3), 630-638.

11. Eisenhart, C., \& Johnstone, B. (2013). Análise do discurso e estudos retóricos. Trad. Kelly Cristina de Oliveira e Moisés Olímpio Ferreira. EID\&A- Revista Eletrônica de Estudos integrados em Discurso e argumentação, 4, 112-126.

Fejes, A. (2008). Governing nursing through reflection: A discourse analysis of reflective pratices. J Adv Nurs, 64(3), 243-250.

Fiorin, J. L. (2005). Linguagem e ideologia. 3.ed. São Paulo: Ática.

Freire, P. (1987). Pedagogia do Oprimido. Rio de Janeiro: Paz e Terra.

Frederiksen, K., Lomborg, K., \& Beedholm, K. (2015). Foucault's notion of problematization: A methodological discussion of the application of Foucault's later work to nursing research. Nursing Inquiry, 22(3), 202-209.

Figueiredo, M. Z. A., Chiari, B. M., \& Goulart, B. N. G. (2013). Discurso do Sujeito Coletivo: uma breve introdução à ferramenta de pesquisa qualiquantitativa. Disturb Comum, 25(1), 129136.

17. Gondim, S. M. G., \& Fischer, T. (2009). O discurso, a análise de discurso e a metodologia do discurso do sujeito coletivo. Cadernos de Gestão Social, 2(1), 09-26..

Haddock-Lobo, R. (2014). A Desconstrução. Revista Cult, 195(17). Recuperado em 04 novembro, 2015, de https://evsmanhoso.wordpress.com/2014/10/24/a-desconstrucao/

Kress, G. (1990). Critical Discourse Analysis. In Melo, I. F. (2009). Análise do discurso e análise crítica do discurso: desdobramentos e intersecções. Revista Eletrônica de Divulgação Científica em Língua Portuguesa, Lingüística e Literatura Letra Magna, 05, 11, pp. 1-18. 
Macedo, L. C., Larocca, L. M., Chaves, M. M. N., \& Mazza, V. A. (2008). Análise do discurso: uma reflexão para pesquisar em saúde. Interface - Comunicação, Saúde, Educação, 12(26), 649-657.

Melo, I. F. (2009). Análise do discurso e análise crítica do discurso: desdobramentos e intersecções. Revista Eletrônica de Divulgação Científica em Língua Portuguesa, Lingüística e Literatura Letra Magna, 05, 11, 1 -18.

Meneses, R. D. B. (2013). A Desconstrução em Jacques Derrida: o que é e o que não é pela estratégia. Universitas Philosophica, 60 (30), 177-204.

23. Mendes, K. D. S., Silveira, R. C. C. P., \& Galvão, C. M. (2008). Revisão integrativa: método de pesquisa para incorporação de evidências na saúde e na enfermagem. Texto contexto enferm, 17(4), 758-764.

Messineo, L., Gentile, M., \& Allegra, M. (2015). Test-enhanced learning: analysis of an experience with undergraduate nursing students. BMC Medical Education, 15, 182.

Minayo, M. C. S. (2004). O desafio do conhecimento: pesquisa qualitativa em saúde. São Paulo: Hucitec/Rio de. Janeiro: Abrasco.

Ministério da Educação. (2001). Diretrizes Curriculares para os Cursos de Graduação. Brasília, DF: Autor. Recuperado em 28 novembro, 2015, de http://www.mec.gov.br/sesu/diretriz.htm

Morin, E. (2001). Os sete saberes necessários à educação do futuro. 3a. ed. São Paulo: Cortez; Brasília, DF: UNESCO.

Orlandi, E. P. (2007). Análise do Discurso: princípios e procedimentos. São Paulo: Pontes.

Paulon, A., Nascimento, J. V., \& Laruccia, M. M. (2014). Análise do Discurso: Fundamentos Teórico-Metodológicos. Revista Diálogos Interdisciplinares, 3(1), 25-45.

Pedroso Júnior, N. C. (2010). Jacques Derrida e a desconstrução: uma introdução. Revista Encontros de Vista, 5, 9-20.

Santos, E. C., Bispo, D. A., \& Dourado, D. P. (2015). A utilização da Teoria Social do Discurso de Fairclough nos estudos organizacionais. Revista Interdisciplinar de Gestão Social, 4(1), 55 73.

Schiavon, I. C. A. (2012). Transposição do modelo tradicional de ensino pelo modelo por competências. Monografia de Especialização, Escola de Enfermagem, Universidade Federal de Minas Gerais, Belo Horizonte.

Souza, D. M. (2009). Representações sociais de idosos sobre o ato de ser cuidado em instituição asilar. Dissertação de Mestrado, Escola da Enfermagem, Universidade Federal da Bahia, Salvador.

Souza, M. T., Silva, M. D., \& Carvalho, R. (2010). Revisão Integrativa: o que é como fazer. Einstein, 8(1), 102-106.

Smith, J. L. (2007). Critical discourse analysis for nursing research. Nursing Inquiry, 14(1), 60 - 70.

Springer, R. A., \& Clinton, M. E. (2015). Doing Foucault: inquiring into nursing knowledge with Foucauldian discourse analysis. Nurs Philos, 16 (2), 87-97.

Tafner, D. P. O. (2013). Princípio da integralidade no processo de formação do técnico de enfermagem das Escolas da REDE SUS. Dissertação de Mestrado, Escola de Enfermagem, 
Universidade Federal de Santa Catarina, Florianópolis.

Taylor, J., Sims, J., \& Haines, T. P. (2012). The influence of protection, palliation and costs on mobility optimization of residents in nursing homes: A thematic analysis of discourse. Int $J$ Nurs Stud, 49(11), 1364-1374.

UNIVERSIDADE FEDERAL DO RIO GRANDE DO SUL (UFRGS). (2015). Escola de Enfermagem da UFRGS. Recuperado em 10 de outubro, 2015, de http://www.ufrgs.br/eenf/

Valore, L. A. (2005). Subjetividade no discurso dos recém-graduados da UFPR. Uma análise institucional. Tese de Doutorado, Instituto de Psicologia, Universidade de São Paulo, São Paulo.

Vianna, P. C. M., \& Barros, S. (2003). A análise do discurso: uma revisão teórica. Rev Min Enf, 7(1), 56-60.

Whitehead, D. (2011). Health promotion in nursing: a Derridean discourse analysis.

Health Promot Int., 26(1), 117-127. 